\title{
Erratum
}

\section{Erratum to "Fuzzy comprehensive evaluation based on multi-attribute group decision making for business intelligence system"}

Wang Chuantao, Cai Xiaofei and Li Baowen

The original verison of this article (10.3233/JIFS-169060) [1] contained a spelling mistake in an author name in reference 15 on page 2212 .

Where it was written:

[15] A. Soloukdara and S.A. Parpanchi, Comparing fuzzy AHP and fuzzy TOPSIS for evaluation of business intelligence vendors, Decision Science Letters 4 (2015), 137-164.

Should have been:

[15] A. Soloukdar and S.A. Parpanchi, Comparing fuzzy AHP and fuzzy TOPSIS for evaluation of business intelligence vendors, Decision Science Letters 4 (2015), 137-164.

The online version of this article has been updated to correct this error.

\section{References}

[1] W. Chuantao, C. Xiaofei and L. Baowen. Fuzzy comprehensive evaluation based on multi-attribute group decision making for business intelligence system. Journal of Intelligent \& Fuzzy Systems 31(4), 2203-2212. Available from: http://dx.doi.org/10.3233/jifs-169060 